\title{
Toxicity, Allergenicity and Carcinogenicity: Some Hope for Innovative Cosmeceutical Products?
}

\author{
Pierre A Guertin* \\ University Hospital of Quebec, University Laval, Canada
}

*Corresponding author: Pierre A Guertin, University Hospital of Quebec, University Laval, Canada, Tel: 418.525 .4444 (ext.48831); E-mail: pierre.guertin@crchudequebec.ulaval.ca

Received: 17 Dec, 2018 | Accepted: 04 Jan, 2019 | Published: 11 Jan, 2019

Citation: Guertin PA (2019) Toxicity, Allergenicity and Carcinogenicity: Some Hope for Innovative Cosmeceutical Products? J Clin Cosmet Dermatol 3(1): dx.doi.org/10.16966/2576-2826.136

Copyright: (c) 2019 Guertin PA. This is an open-access article distributed under the terms of the Creative Commons Attribution License, which permits unrestricted use, distribution, and reproduction in any medium, provided the original author and source are credited.

\begin{abstract}
The safety of cosmetic and cosmeceutical products has been questioned by several independent experts. A plethora of ingredients, additives and preservatives, used in their preparation are indeed allergenic, toxic, mutagenic and carcinogenic. Despite warnings from Dr. David Suzuki and others a few years ago, little has been done by authorities or the industry to improve the safety of these products. Some companies have instead begun proposing dermatological creams and serums composed of natural ingredients. However the safety profile of those newer products for the intended indication remains generally to be determined clearly. Authorities such as the US Food and Drug Administration, Health Canada and European Medicines Agency should be asked to implement new rules to improve regulations before approval and commercialization of cosmetic and cosmeceutical products that include so-called 'natural' ingredients or not.
\end{abstract}

\section{Main Text}

The epidermis, basement membrane, dermis and hypodermis are the four main layers that constitute the skin which main role is to protect against infections and heat losses [1]. Unfortunately, those layers are not completely impermeable - absorption of chemicals through them has been clearly shown [2]. Aluminum is a good example. It has been shown to be absorbed through viable human stripped skin and may increase breast cancer when used in antiperspirants [3]. Other ingredients such as dyes, fragrances or chemicals aimed at increasing stability and shelf-life duration are also often associated with safety issues - e.g., butylated hydroxyanisole and butylated hydroxytoluene or coal tar dyes, Diethanolamine (DEA)-related ingredients, dibutyl phthalate, formaldehyde-releasing preservatives, parabens, fragrance, Polyethylene Glycols (PEG) compounds, petrolatum, siloxanes, sodium laureth sulfate, triclosan are found in almost all currently available, industrially-manufactured skin health or skin care products. For a rather exhaustive list, visit David Suzuki's website [4,5].

As of today, dermatological, skin care and anti-ageing products are not significantly assessed, approved, or authorized prior to commercialization in North America and and Europe [5] - only a short list of ingredients can't be used or can be used only in low concentration.

Most countries prefer instead to simply impose limits associated with claims that are permitted. No claim about therapeutic efficacy is allowed but terms such as 'improvement of skin appearance e.g., shinier, brighter, younger-looking, remain legal. Indeed, claims about improvement of functions or therapeutic-like effects would remove those products from the 'cosmetic and cosmeceutic' class to put them into the 'drugs and therapeutics' category associated with much stricter rules and greater development costs.

In fact, developing a new drug treatment with therapeutic claims may cost from bench to bedside as much as $\$ 2.5$ billion dollars and between 12 and 15 years of tests before becoming eligible for approval [6]. Drug development includes several successive steps including research and discovery, preclinical testing (i.e., toxicology and safety pharmacology in animals and animal tissues) as well as studies in humans (called clinical trials) i.e., phase I ( $<50$ healthy volunteers), phase II (50-150 patients), phase III studies (up to several thousand patients from different countries) and post-market surveillance (also called phase IV) studies [7]. This expensive process is financially feasible for pharmaceutical companies. However, for cosmetic and cosmeceutical companies that have less revenues, it would impossible to impose comparable sets of rules and regulations.

As such, no extended development path and no valid placebocontrolled clinical trial for the intended use of a new product need to be conducted for commercialization of cosmetics and cosmeceuticals [7]. Yet, many additives and specifically preservatives associated with significant, potentially life-threatening, safety concerns are being used essentially to increase shelf-life duration that is the 
time post-manufacturing after which stability, pathogens, yeast, fungi, molds, oxidative alterations, and bacterial levels can reach unacceptable levels [8-10].

Yet, some solutions exist now to reduce the use of unsafe ingredients. New packaging strategies such as dispensers with airless technology - i.e., a system that enables a difference in environmental pressure creating an airless vacuum capable of expulsing only to the outside (one-way) a liquid or a cream from a reservoir once the valve is opened, could be used to increase safety related with shelf-life-related problems [11]. The amounts of additives/preservatives could be reduced if justin-time approaches were to be applied such as in the food industry. The use of ultra pure water - e.g., reverse-osmosis water systems are considered among the best filtering devices for getting great water purity, could also help reducing the use of unsafe preservatives [12].

The authorities have still not modified rules and regulations regarding the approval of cosmetic products. Indeed, no clinical data demonstrating safety is required from manufacturers. Often, instead, they use other ingredients in replacement of those known or suspected of safety issues. However, these 'greener' or organic molecules don't typically have a safety profile demonstrated clinically despite claims otherwise.

For instance, propanediol (1,3-propanediol), an ingredient increasingly used by the industry for electronic cigarettes, personal care creams and anti-ageing serums. For some skin care purposes, it is used to enhance the transdermal absorption of other ingredients (e.g., the actives) enabling moisturizing effects and skin smoothness to be improved. Propanediol is derived from corn and thus is presented as 'green' and safe [13]. But, we know from a few studies that topical application of 1,3-propanediol on human skin may occasionally cause mild irritation as shown also in rabbits [14]. A case report published in 2008 revealed the death of a woman who drank the content of two antifreeze containers comprising 1,3-propanediol [15]. No ethicallyapproved clinical studies have yet been undertaken to study the safety and toxicity of 1,3-propanediol when regularly applied on human skin (clinicaltrials.gov).

Another example is glycerin and some of its related compounds such as polyglycerin-10 used by the industry in the making of so-called eco-friendly and safe personal care products. They are humectants found naturally in lipids (e.g., vegetal origin) that are used in some moisturizers and anti-ageing products [16]. No evidence of genotoxicity and carcinogenicity has been found in rats but mild irritating effects were reported in guinea-pigs [17]. In humans, one patient with eczema who topically applied glycerin was reported to experience significant skin reactions 48 hours post-exposure. Incidence of recurring pruritic erythema in an 80-year-old woman using polyglycerin esters has been found whereas $7 \%$ Polyglyceryl-2 Isostearate was shown to elicit slight dermal irritation in other individuals [18-19].

Alcohol or ethyl alcohol (a.k.a. ethanol) is also often utilized to control mold growth and bacterial development in replacement of carcinogenic preservatives. As such, it has become a key ingredient of many organic cosmetics. Although some studies have reported no sign of irritation at low doses (i.e., such as in most skin care products), dryness, or allergy caused by alcohol [20], it remains unclear the extent to which it does not contribute to alteration of the skin barrier and hence to the potential mutagenocity of other ingredients. Indeed, since it is known to increase laxity of the lipid packing while stimulating vasodilatation of blood vessels of superficial skin layers [21,22], it may probably further enhance skin penetration into the blood stream [2123] of problematic ingredients such as dyes, fragrances and others hazardous compounds listed by David Suzuki.

\section{Conclusion}

The safety of cosmetic and cosmeceutical products is an increasing concern among the population. Hundreds of toxic ingredients are still being used by the industry mainly for color, odor, chemical stability or shelf-life duration reasons. Although no change in rules and regulations has been introduced yet by authorities, new products that comprise instead supposedly greener, safer and organic ingredients are continuously being proposed on the market. However, beyond marketing arguments, most of those 'better' products remain without significant safety data to support their claims. At least, several companies are now avoiding the use of phthalates, dyes, parabens and fragrances while taking advantages of new packaging technologies - e.g., airless dispensers, ultra-pure water, to reduce the amounts of preservatives needed. This said, approval for commercialization of cosmetic products without evidence of safety in humans should not be accepted for public health reasons. Claiming that no safety concern exists without having conducted proper clinical studies is bound occasionally to lead a type of mistake well-known in science - the type II error (a.k.a. false negative) which is a failure to detect an existing effect or an adverse event that could be uncovered if tests were to be conducted properly.

\section{References}

1. McGrath JA, Eady RAJ, Pope FM (2004) Anatomy and Organization of Human Skin. In: BurnsT, Breathnach S, Cox N, Griffiths C (eds) Rook's Textbook of Dermatology. $7^{\text {th }}$ Edition, Blackwell Publishing, USA 3.13.6.

2. Bos JD, Meinardi MM (2000) The 500 Dalton rule for the skin penetration of chemical compounds and drugs. Exp Dermatol 9: 165-169.

3. Pineau A, Fauconneau B, Sappino AP, Deloncle R, Guillard O (2014) If exposure to aluminium in antiperspirants presents health risks, its content should be reduced. J Trace Elem Med Biol 28: 147-150.

4. Draelos ZD (2009) Cosmeceuticals: undefined, unclassified, and unregulated. Clin Dermatol 27: 431-434.

5. The Dirty Dozen cosmetic chemicals to avoid. David Suzuki Foundation.

6. DiMasi JA, Grabowski HG, Hansen RW (2016) Innovation in the pharmaceutical industry: New estimates of R\&D costs. J Health Econ 47: 20-33.

7. Ciociola AA, Cohen LB, Kulkarni P, FDA-Related Matters Committee of the American College of Gastroenterology (2014) How drugs are developed and approved by the FDA: current process and future directions. Am J Gastroenterol 109: 620-623.

8. Verhulst L, Goossens A (2016) Cosmetic components causing contact urticaria: a review and update. Contact Dermatitis 75: 333-344.

9. Nigam PK (2009) Adverse reactions to cosmetics and methods of testing. Indian J Dermatol Venereol Leprol 75: 10-18.

10. Darbre PD, Harvey PW (2014) Parabens can enable hallmarks and characteristics of cancer in human breast epithelial cells: a review of the literature with reference to new exposure data and regulatory status. J Appl Toxicol 34: 925-938.

11. Shivsharan US, Raut ES, Shaikh ZM (2014) Packaging of cosmetics: a review. J Pharm Sci Inn 3: 286-293.

12. Wiemer KE, Anderson A, Stewart B (1998) The importance of water quality for media preparation. Hum Reprod 13: 166-172. 
13. Guertin PA (2018) Is Propanediol a safer molecule than some other glycols in personal care and anti-aging biocosmeceutical products? Int J Aging Res 1: 23.

14. Belcher LA, Muska CF, DeSalvo JW (2010) Evaluating 1,3-Propanediol for Potential Skin Effects. Cosmetics and Toiletries 125.

15. Garg U, Frazee CC $3^{\text {rd }}$, Kiscoan M, Scott D, Peterson B, et al. (2008) A fatality involving 1,3-propanediol and its implications in measurement of other glycols. J Anal Toxicol 32: 324-326.

16. Guertin PA (2018) How safe are glycerin and polyglycerin-10 as key ingredients in personal care products? Clin Pharmacol Toxicol Res 1: $1-2$.

17. Lillian C Becker (2014) Safety Assessment of Glycerin as Used in Cosmetics. CIR's scientific literature review for final report.

18. World Health Organization (WHO) Toxicological evaluation of some antimicrobials, antioxidants, emulsifiers, stablizers, flour-treament agents, acids and bases. Polyglycerol esters of fatty acids.
19. Washizaki K, Kanto H, Yazaki S, Ito M (2008) A case of allergic contact dermatitis to polyglyceryl laurate. Contact Dermatitis 58: 187-188.

20. Pendlington RU, Whittle E, Robinson JA, Howes D (2001) Fate of ethanol topically applied to the skin. Food Chem Toxicol 39: 169174.

21. Merle C, Baillet-Guffroy A (2009) Physical and chemical perturbations of the supramolecular organization of the stratum corneum lipids: in vitro to ex vivo study. Biochim Biophys Acta Biomembr 1788: 10921098.

22. Guessant C, Marty JP, Dupont C (1993) Measurement of cutaneous blood flow by laser Doppler velocimetry. Importance of probe effect and solvent effect after topical application. Therapie 48: 151-155.

23. Brand RM, Jendrzejewski JL, Charron AR (2007) Potential mechanisms by which a single drink of alcohol can increase transdermal absorption of topically applied chemicals. Toxicology 235: 141-149. 